\title{
Memória das atividades realizadas junto aos povos Puruborá e Kujubim, Rondônia, constantes em dois relatórios de viagem do regional do CIMI/RO, de 2015 e 2017
}

\author{
Rondônia. Teaching Memory of activities carried out with the \\ Puruborá and Kujubim peoples, Rondônia, included in two \\ CIMI / RO regional travel reports for 2015 and 2017
}

Ruth Maria Fonini Monserrat ${ }^{1}$

Recebido em março de 2018

Aceito em maio de 2018

Resumo:

Reúno aqui memórias de atividades de pesquisa e ensino de duas línguas outrora faladas no Estado de Rondônia, o Kujubim (família Txapakúra) e o Puruburá (família Puruborá, tronco Tupí). As atividades foram realizadas em comunidades Puruborá e Kujubim com a participação de professores locais e lembradores de suas respectivas línguas. As informações trazidas revelam também o estado da arte do material linguístico existente sobre as duas línguas e como os Puruborá e Kujubim concebem o ensino do que é possível reaver das línguas de seus ancestrais.

Palavras-chave: Puruborá. Kujubim. Línguas lembradas. Rondônia. Ensino de Línguas não mais faladas.

\begin{abstract}
:
I present memories of research activities and teaching of two languages once spoken in the State of Rondônia, the Kujubim (Txapakúra family) and Puruburá (Puruborá family, Tupí stock). The activities were carried out in communities Puruborá and Kujubim with the participation of local teachers and reminders of their respective languages. The information provided also reveals the state of the art of the linguistic material existing on the two languages and how the Purubora and Kujubim conceive the teaching of what is possible to recover from the languages of their ancestors.
\end{abstract}

Keywords: Purubora. Kujubim. Languages recalled. Rondônia. Teaching of Languages no more spoken.

\footnotetext{
${ }^{1}$ Doutora em Linguística pela Universidade Federal do rio de Janeiro, professora aposentada da Faculdade de Letras da Universidade Federal do Rio de Janeiro. É assessora linguística de vários projetos de Educação Escolar Indígena.
} 


\section{Memória das atividades junto ao povo Puruborá 2}

As atividades com o povo Puruborá foram realizadas num primeiro momento na Escola Indígena Estadual de Ensino Fundamental "Ywará Puruborá" da aldeia Aperoy. No dia 26 e na manhã do dia 27/08, visitamos várias famílias e pudemos socializar o objetivo de nossa presença e convidar a todos - adultos e crianças - para, na parte da tarde, participar de uma aula na língua materna e também para celebrar o aniversário de Hosana, a Cacique da Aldeia.

Convém esclarecer inicialmente que a língua puruborá é dada como língua morta: na verdade, os trabalhos linguísticos que puderam ser feitos, limitam-se a listas vocabulares e a poucas frases (Moserrat 2005; Galúcio 2005, 2013). Não há mais falantes que possam utilizar a língua como forma de comunicação plena. O único sobrevivente que ainda conserva, bem precariamente, a memória lexical da língua, é Paulo Aporeti, um idoso de cerca de 90 anos, enfermo e enfraquecido. É nele que se apoia, em seu desejo de aprender a língua de seu povo (no que ainda for possível) e de ensiná-la às crianças, o jovem Professor da língua materna, Mario de Oliveira Neto (mais conhecido como Gi). Ele tem fé, ele tem esperança de que ainda é possível, sim, voltar a falar em puruborá.

A aula foi ministrada pelo professor Gi. Ele pediu a todos os presentes os alunos e seus pais puruborá, bem como os visitantes não indígenas - que tentassem escrever em puruborá uma série de palavras que ele iria ditar. Antes, foi apresentado o alfabeto da língua e a pronúncia das letras que são diferentes das do português ou, quando as letras são as mesmas do português, com outros sons.

Alfabeto puruborá: $a, \hat{a}, b, d, e, h, i, j, k, m, n, o, p, r, t, u, w, y, ?$ Há também vogais (nasais) com til: ã, ẽ, ̃̃, õ, ũ, y

O ditado consistiu de 12 palavras. As crianças "tiraram de letra", acertaram muito mais que os adultos. Houve o treino da pronúncia, palavra por palavra, pessoa por pessoa, bem como a tradução delas para o português. Eis as palavras trabalhadas, em sua grafia correta: wabâj, wâ, wât, wytoa, wyria, waryp, wĩ, wüp, wy, wyta, wyj, woapa.

A seguir, o professor ditou duas frases: Mâj wyj win xibyt xuruk 'Vamos ao rio matar com flecha piranha'. E Oajã xibyt kapixe wyta dede. 'Minha mãe cozinha muito gostoso'.

Depois disso, fez um exercício em que, a partir de oito palavras soltas em português escritas no quadro (as mesmas do ditado), a instrução era que

\footnotetext{
${ }^{2}$ Conforme programação feita pelo regional do CIMI/RO para 2015, a equipe responsável pelas atividades - Volmir Cândido Bavaresco e Emilia Altini - juntamente com a assessora de Linguística Ruth Monserrat, da UFRJ/RJ, estiveram reunidos com representantes do povo Puruborá na aldeia Aperoy - BR 429, Km 32, Rio Manoel Correa, município de Seringueiras / RO, entre os dias 26 e 29 de agosto de 2015, e com representantes do povo Kujubim, em Costa Marques / RO, entre os dias 30 de agosto e 02 de setembro de 2015.
} 
os alunos formassem frases em puruborá com elas. Eis as palavras: piranha, assar, muito, minha mãe, vamos, matar, flechar, rio. Deu certo. Observação: O professor Gi sabe que está faltando a 'gramática', a ligação entre as palavras, e por isso ele precisa conversar com seu tio Paulo para que este lhe diga como fazer (se puder se lembrar). Mas no caso da locução 'minha mãe', por exemplo, que em português é formada por duas palavras, ele sabe que em puruborá há uma só palavra, com o possessivo ligado ao nome: oajã (ou seja, o-ajã).

Depois da aula festejamos o aniversário de 54 anos de Hosana, que pela primeira vez na vida ganhou um bolo, segundo suas palavras. Foi um momento muito bonito de congraçamento na escola, com a presença de muitas pessoas da comunidade. Valeu!!

No dia 28 pela manhã nos dirigimos à casa de Gi, onde pudemos sentir toda sua disposição, garra e vontade política de estudar e aprender a língua materna de seus avós. Os puruborá podem, sim, contar com um membro do povo que luta por isso. Estava presente também o Professor que atende os alunos do $1^{\circ}$ ao $5^{\circ}$ ano, Deivid Lobato da Silva, e ainda Marinez Castro de Oliveira e Valterli Acácio Lobato (todos Puruborá). Iniciando as atividades do dia, Gi nos contou de sua dificuldade quanto à fala e escrita de frases. Ele sente a necessidade de ter alguns pronomes - eu, tu, nós, etc. Começamos a fazer com ele uma lista de coisas que ele devia conseguir explicitar com o parente Paulo Aporéti. Em relação ao tempo: agora, depois, antes, hoje, amanhã, ontem, antigamente. Aos numerais: $1,2,3$, gêmeos, muitos, poucos (em comparação com muito, pouco): muitas pessoas, muito gostoso. Aos possessivos: meu, teu, dele, etc. Outros conceitos, como: pequeno, muito pequeno, grande, muito grande, muito (dede) pouco; grosso, fino; alto, baixo; curto, grosso; em cima, embaixo; dentro, fora, frente, atrás; perto, longe; largo, estreito; esquerdo, direito; torto, reto; liso, enrugado; cedo, tarde; vazio, cheio; fundo, raso; duro, mole; sim, não; cheiroso, fedido; triste, alegre; bonito, feio; bom, ruim; fácil, difícil; eco, grito; claro, escuro; visível, invisível; aberto, fechado; mais, menos; certo, errado; brilhoso, opaco, pontudo; nu e pelado. Cores: branco, preto, vermelho, verde, amarelo. Interrogações: onde?, quando?, quem?, como?, de onde?, para onde?, de quem?, para quem?, qual?, por que? Tempos e aspectos verbais: pescar; eu vou pescar; eu quero pescar; eu sei pescar; eu não sei pescar; antigamente eu pescava muito; agora não pesco mais; não gosto de pescar; não quero trabalhar; hoje não posso trabalhar; eu trabalho muito; estou trabalhando; ontem eu estava trabalhando. Imperativo: estude!; coma!; não coma!; não mate! Diferença entre: eu não como porco espinho; eu não comi porco espinho.

Frases encontradas no livro sobre bichos, em puruborá, produzido pela linguista Ana Vilacy, do Museu Goeldi, com a participação de Gi Mário Puruborá e Paulo Aporeti (2013): Eu quero comer porco espinho. - Õt apyka orteka. Eu vi macaco suin. - Ót axakit dopa. Eu não vi macaco preto. - Õt axakit dopa kinõp. Eu não como macaco preto. - Õt motayãro kinõp. Você 
come porco espinho. - 2ẽt motayãro. Eu quero comer. - Õt arykasoteka; Eu trabalho muito. - Õt motãja okinĩp. Eu vi. - Õtrakit dopa - Eu não vi. - Õtrakit dopa kinõp; Vamos. Mãj baxuki arkaro. Eu tenho. - Õt ameko wewap.

Foi um dia de grande movimentação e atenção com o estudo e aprendizado da língua. Foi iniciada a digitação do material do levantamento linguístico, que consta de aproximadamente 800 palavras. O professor Gil recebeu orientação da linguista Vilacy, do Museu Goeldi, quanto ao alfabeto e à escrita das palavras que ela coletou, mas nenhuma orientação pedagógica e metodológica para o ensino da língua no processo da educação escolar indígena. Os membros da comunidade puruborá deixaram claro que não têm mais nenhuma ligação ou compromisso de trabalho com Vilacy, tendo inclusive solicitado cópia de tudo o que ela tinha sobre a língua, escritos, gravações etc. No final da tarde ficou como encaminhamento que Mario (Gi) iria na segunda feira a Costa Marques para passar o dia tirando dúvidas a respeito dos seus dados e aprendendo tudo o que desse para aprender com um dos últimos falantes da língua materna, o Paulo Aporeti. Quanto a nós, também estaríamos em Costa Marques, trabalhando com o povo Kujubim.

\section{Memória das atividades junto ao povo Kujubim}

Foi na casa de Vitor Kujubim e esposa Gesabel que se desenvolveram as atividades. Estavam presentes, além dos donos da casa, seus filhos - Francismar (Mocinha), Ivaneide (Nena), João (Neto), Divina (Ina) e Willians Viana da Silva Filho (Lilinho) - este com a esposa, Sandra Viana, e o filhinho. Estava também a tia Rosa. Todos da mesma família Kujubim. O objetivo do trabalho era verificar o que ainda era possível resgatar da língua Kujubim para utilizar no processo de reafirmação étnica do povo e, se possível, para produzir material didático para o aprendizado da leitura e da escrita em Kujubim na escola. O único material disponível eram dois trabalhos de linguística - uma dissertação de mestrado sobre a fonética e a fonologia da língua e uma lista lexical comparativa de línguas da família Txapakura, à qual pertence o Kujubim -, além de duas listas de palavras coletadas pelas netas de Dona Francisca (já falecida), Francismar e Marli, por ocasião de duas Assembleias do povo. Durante a realização primeira, em 24 e 25 de julho de 2002, foram coletadas, entre outras, as seguintes palavras: macaco-juim; porco-tocoam; anta-emim; macaxeira-acop; jacu - thianthan; batata doce - aru timam, ditas por Dona Suzana Mo'aw Kujubim. $\mathrm{Na} 10^{\mathrm{a}}$ Assembleia, que também se realizou na casa de Vitor Cujubim, surgiram novas palavras, como: kujubim - kutruye; mutum-utim; jacu-txâtxã (txãtxan); macaco - uwaran; macaco prego - juwin; traira - tikin; cara - sakau(w); piau juran; mandi - apoo; quebra galho - wramazam; piranha - apue; onça pintada - kinan; porco do mato - tokuan; quati - kapozaap; jacamim - irum; veado jimoop; macaco velho - emirop; guariba - uram; cutia-pimon; paca-mekop; 
veado vermelho - toam; tracajá - toa; nambu azul - izamoop; nambu galinha - wanan; anta - emĩ̃; cobra - krakau; banana brava - ritam; açaí - iran; batoá - txawan.

No primeiro momento do nosso encontro com o grupo, os presentes fizeram um relato sobre a história do povo e todas as tentativas e esforço para o levantamento linguístico. Havia vários materiais de levantamentos lexicais feitos por pesquisadores e estudantes de mestrado, e pelo professor Henri Ramires, da UNIR/RO, com muitas palavras. Nos apontamentos de Francismar (mocinha) havia uma anotação sobre a pintura do povo: "Quando o povo se pintava de vermelho (urucum) estava pronto para a guerra e quando se pintava com listas pretas (de jenipapo) e listas vermelhas (de urucum) estava em festa. A pintura em listas, com jenipapo e urucum, era feita no rosto, peito e membros superiores e inferiores. A pintura só com jenipapo era passada no corpo todo".

A assessora ouviu de Vitor Kujubim informações sobre a localidade Santa Fé - de onde é oriunda sua esposa Gesabel - "que tem muita história". Era uma comunidade que foi iludida por um fazendeiro, e o povo de lá acabou expulso da terra. Agora estão lutando, com o apoio de Igreja Católica. Foram o Pe. Paulo, o bispo Dom Geraldo e as irmãs que começaram a luta. O fazendeiro estava plantando capim, isso em 1986. O povo tinha só um advogado, o Dr. Negrão, que ganhou a questão. As famílias foram todas de volta (o fazendeiro tinha queimado todas as casas). A comunidade é dos moradores, mas não tem ainda a documentação. Em 2001, veio o reconhecimento institucional do direito dos remanescentes de quilombos. Foi criada então uma diretoria. $\mathrm{O}$ antropólogo que fez o laudo antropológico é Samuel. A Associação foi reconhecida oficialmente, e a comunidade ficou chamada de Comunidade Quilombola de Santa Fé. Mas daí por diante ficou tudo parado, e começou a haver várias invasões e contestações. O Dr. Henrique (Procurador da república em Ji Paraná/RO) reafirmou que a comunidade era quilombola; ele deve ir em setembro lá em Costa Marques e vão conversar sobre esse assunto, para os quilombolas conseguirem o titulo definitivo de posse da terra.

Soubemos ainda, por meio de Vitor Kujubim, que no rio Azul - Porto Moré, há índios da etnia Moré, mas o povo chama de Xapacura. As irmãs de Surpresa vão direto lá, toda semana. As casas são cobertas de sororoca (espécie de bananeira brava). Vitor conhece bem lá. Fazia visita com o Pe. Zezinho, (hoje casado com Rosemeire, missionária do Cimi) para instalar placa solar. Ele diz que tem mais ou menos uns 60 moradores, e tem escola com professores bolivianos.

Na sequência dos trabalhos, a assessora fez uma reflexão, com os presentes, membros do povo, sobre a questão da ortografia da língua, que tinha de ser feita a partir do material lexical de que se dispunha. Orientou e animou os participantes, afirmando que sempre é possível e compensador para um povo 
recuperar pelo menos uma parte da língua, quando não é mais possível recuperála toda. Salientou que o povo Kujubim tem uma vantagem nessa luta: é que, mesmo tendo perdido seus falantes, eles dispõem de cerca de 800 palavras, e que isso pode ajudar bastante para a comunicação oral e escrita na escola, e também para a comunicação entre os membros da comunidade kujubim. Tarefa urgente, para que se possa pôr isso em prática, é localizar as gravações já feitas que, segundo os presentes, estão com o doutor Gilles em Guajará Mirim, e também buscar junto a Irene Kujubim, irmã de Rosa, mais informações sobre os dados coletados, sobre quem os coletou e como fez isso.

Em seguida, passou-se à escolha das palavras mais fáceis dentre as disponíveis nas listas vocabulares coletadas, para ter maior segurança, num primeiro exercício de treinamento da fala e da escrita entre os membros das famílias participantes no encontro.

Na manhã do dia 31 foi feita cópia do material trabalhado no dia anterior, para o grupo presente (Lilinho, sua esposa Sandra e o filhinho, Rosa e João) poder exercitar a pronúncia e leitura das palavras escolhidas pelos participantes. $\mathrm{Na}$ parte da tarde chegaram também as três filhas do casal, Nena, Mocinha e Divina, que retornavam do trabalho, pois são funcionárias públicas. E passamos mais uma tarde estudando com pessoas do povo e tirando várias dúvidas sobre a ortografia e fala de sua língua tradicional indígena.

No dia 01 de setembro pela manhã fomos com Mario Puruborá à casa de Paulo Aporeti, para tirar dúvidas e aprender mais, com ele, sobre a língua Puruborá. Na parte da tarde retornamos para a casa de Vitor Cujubim para mais um momento de revisão da ortografia, leitura e exercícios de pronúncia de sons de palavras em Cujubim.

Foi encerrado esse momento de estudo com uma avaliação positiva. Mesmo sem falantes ativos da língua, há uma grande chance de recuperar boa parte dos sons da língua e poder vir a falar, assim, muitas palavras e frases. Nada se perde, tudo se constrói com esforço e vontade, isso observamos no grupo participante no estudo.

Encerrando as atividades, foi elaborado um documento solicitando agilidade no processo de demarcação do território cujubim e pedindo a retirada dos invasores na terra retomada.

Retomamos a viagem de volta a Porto Velho no dia 02, com uma parada na casa de Hosana Puruborá, onde foi elaborado um documento informando a Seduc que a comunidade Puruborá reafirma seu desejo de continuar tendo como professor de língua materna o professor Mário - não aceitando sua substituição por nenhum outro professor, mesmo que seja do povo -, pois ele é quem detém toda a prática da escrita e da fala da língua materna na escola. 


\section{Emilia Altini e Ruth Monserrat}

Em novembro de 2017 houve novo encontro da equipe do Cimi/Rondônia com o povo Kujubim, em Costa Marques, e com o povo Puruborá, em Seringueiras, na aldeia Aperoy, do Rio Manuel Correia - BR 429.

\section{Kujubim}

As atividades desenvolvidas junto aos Kujubim no encontro de 2017 concentraram-se no treinamento da pronúncia, escrita e identificação das palavras constantes na lista gravada no ano anterior pela assessora. Essa lista, revista e ampliada com novas palavras, foi novamente gravada, em kujubim e português, sendo cada palavra indígena pronunciada três vezes. Nota-se o interesse crescente pelo conhecimento desse aspecto da língua, entre os participantes, agora já em maior número. Infelizmente, ainda não se deu o contato com os Moré, nem a recuperação do material ainda em mãos de terceiros. Quero, então, relembrar aqui o que ocorreu nos dois primeiros encontros com o povo Kujubim, em 2015 e 2016. As atividades foram realizadas em Costa Marques, com vários membros da comunidade reunidos na casa de Vitor Kujubim e Gesabel, sua esposa. Os presentes fizeram um relato sobre a história do povo e as tentativas e esforços para reunir material sobre a língua kujubim. Os únicos materiais disponíveis sobre a língua eram, além de dois trabalhos de linguística - uma dissertação de mestrado sobre a fonética e a fonologia da língua e uma lista lexical comparativa de línguas da família Txapakura (à qual pertence o Kujubim) -, duas listas de palavras coletadas pelas netas de Dona Francisca (já falecida), Francismar e Marli, por ocasião de duas Assembleias do povo Kujubim. (Essas listas estão transcritas no relatório do encontro de junho de 2015). O objetivo do nosso trabalho foi então de, na medida do possível, enfrentar o estudo da língua Kujubim, para incentivar seu aprendizado e utilização no processo de reafirmação étnica do povo. No primeiro momento esse trabalho consistiu na seleção, dentro das listas disponíveis, das palavras mais fáceis, mas ao mesmo tempo mais representativas do ponto de vista da abrangência de todos os sons da língua, para o treinamento dos participantes na leitura, escrita e reconhecimento dessas palavras. Foram providenciadas cópias do material para cada um dos participantes. Para melhor poderem continuar o aprendizado, fora dos encontros, o grupo sugeriu que a assessora gravasse a lista, lendo as palavras. Todos ficaram satisfeitos e com mais ânimo para seguir estudando a língua. Mas a assessora salientou que não há tanta segurança de que as palavras lidas por ela reflitam realmente a pronúncia de um falante nativo, já que sua interpretação está fundada em material escrito, não na pronúncia real de um Kujubim. Por isso, reitera, é tão importante recuperar as gravações existentes e gravar o que Irene porventura ainda se lembre da língua. Houve uma reflexão sobre a questão da ortografia da língua, que infelizmente tinha de 
ser feita a partir do material lexical de que se dispunha. A assessora orientou e animou uma vez mais os participantes, afirmando que sempre é possível e compensador para um povo recuperar nem que seja só uma pequena parte da língua, quando não é mais possível recuperá-la toda. Salientou ainda que o povo Kujubim tem uma vantagem nessa luta: é que, mesmo tendo perdido seus falantes, eles dispõem de cerca de 800 palavras, e que isso pode ajudar bastante para a comunicação oral e escrita na escola quando o povo retomar sua terra, e que também vai ser útil na comunicação entre os membros da comunidade Kujubim. Reiterou a necessidade e urgência de tentar localizar as gravações que, segundo informações, parecem estar com o doutor Gilles em Guajará Mirim. É preciso, além disso, ver junto a Irene Kujubim, irmã de Rosa, se é possível obter mais informações sobre os dados coletados pelas meninas (cf. relatório do primeiro encontro sobre a língua). E, além do mais, tentar contato com os índios da etnia Moré, chamados de Txapacura pela população, que, segundo Vitor, moram do rio Azul.

\section{Puruborá}

O estudo da língua materna com alunos e comunidade teve a presença de 17 pessoas. O Gi (Mario) de Oliveira Puruborá, professor da língua materna, pela manhã trabalha só com as crianças e à tarde com todos da comunidade que têm interesse em falar e escrever e conversar o que for possível na língua Puruborá. Foram dois dias de estudo com o acompanhamento da assessora linguística Ruth. Sobre o trabalho com a língua materna indígena, eis seu depoimento:

As atividades nessa etapa, como nas anteriores, foram realizadas na Escola Indígena Estadual de Ensino Fundamental "Ywará Puruborá” da aldeia Aperoy. O trabalho desta vez concentrou-se na revisão do material puruborá digitalizado em forma de livro por Bonita, organizado pelo professor Gi com a colaboração do professor Deivide. O livro contém o alfabeto puruborá, um vocabulário em ordem alfabética puruborá-português, e seleções de frases em puruborá, com vários exercícios para os alunos. Tem cerca de 40 páginas. As atividades incluíram também duas aulas do professor Gi, nas quais participaram ativamente não apenas as crianças, mas também muitos jovens e adultos, além dos membros da equipe do Cimi, do visitante José e da assessora Ruth. Nos exercícios de pronúncia, as palavras ditadas pelo professor eram repetidas individualmente, com grande interesse, por todos os presentes. Os progressos são evidentes, embora se saiba que não existem as condições necessárias para poder recuperar a língua em toda sua riqueza de língua plena, usada ativa e cotidianamente por um povo. A propósito, acho pertinente citar aqui um trecho do relatório de 2015: “Convém esclarecer inicialmente que a língua puruborá é dada como língua morta: na verdade, os trabalhos linguísticos que puderam ser feitos, limitam-se a listas vocabulares e a poucas frases. Não há mais falantes que possam utilizar 
a língua como forma de comunicação plena. O único sobrevivente que ainda conserva, bem precariamente, a memória lexical da língua, é Paulo Aporeti, um idoso de cerca de 90 anos, enfermo e enfraquecido. É nele que se apoia, em seu desejo de aprender a língua de seu povo (no que ainda for possível) e de ensiná-la às crianças, o jovem Professor da língua materna, Mario de Oliveira Neto (mais conhecido como Gi). Ele tem fé, ele tem esperança de que ainda é possível, sim, voltar a falar em puruborá”.

\section{Referências}

Galúcio, Ana Vilacy; Puruborá, J. E. ; Aporete FIlho, P. . Vocabulário Ilustrado: Animais na língua Puruborá. 1. ed. Belém: MPEG,. v. 1. 95p, 2013.

Galúcio, Ana Vilacy. "Puruborá: notas etnográficas e linguísticas recentes". Boletim do Museu Paraense Emílio Goeldi — Série Ciências Humanas, vol. 1, no . 2: 159-192, 2005.

Monserrat, Ruth Maria Fonini . Notícia sobre a língua Puruborá. In: Ana Suelly Arruda Câmara Cabra; Aryon Dall'Igna Rodrigues. (Org.). Novos Estudos sobre Línguas Indígenas. 1ed.Brasília: Editora UnB, v. , p. 9-22, 2005. 